\title{
Una Magdalena penitente de los hermanos García. Nueva escultura y tema para su catálogo de terracotas
}

\author{
José Javier Gómez Jiménez \\ Universidad de Granada \\ josejaviergomezjimenez@gmail.com
}

El catálogo de obra de los célebres hermanos gemelos Miguel Jerónimo García (Granada, 1576-1639) y Jerónimo Francisco García (Granada, 1576-1644) continúa, por fortuna, acrecentándose con destacables hallazgos. En este caso atribuimos a su autoría, tanto por técnica y estilo, un altorrelieve de terracota policromada de reducidas dimensiones $(26 \times 22,5 \times 6 \mathrm{~cm}$ ) que representa a María Magdalena como penitente y que ahora se documenta y muestra por primera vez al poder acceder al oratorio particular de una casa de Granada donde se conserva'.

La imagen [1], que bajo llave se exhibe dentro de una urna dorada del siglo XVIII embellecida con cincelados y rocallas, posee una excelente calidad ejecutiva atenida al gusto naturalista del primer Barroco, a la vez que emana una intensa comunicación de gran expresividad y elocuencia por su penetrante sentido doliente y sensual -aunque se trata de un dolor contenido alejándose de cualquier exceso tétrico en la exposición del asunto del eremita que muestra su austeridad, silencio y renuncia al cuerpo, a veces de manera descarnada, en su camino a la santidad-.

Singulariza la obra, en aportaciones de interés, el tema elegido que supone un registro iconográfico nuevo en la producción de los artistas, que diversifica la entidad de sus tradicionales y abundantes representaciones sobre el Ecce Homo, san Jerónimo penitente y san Juan Bautista en el desierto. A ello se suma el atractivo de ser una santa la protagonista; hecho excepcional ante lo escaso de trabajos de contenido femenino que realizaron los García conociéndose tan solo unos bustos en relieve de la Dolorosa.

Asimismo, es de atención la correcta y bella anatomía idealizada del desnudo ofrecido de la espalda y del pecho -aunque velado por un brazo y dedos extendidos de una mano adecuándose a las prescripciones de decoro- que, por su insinuación erótica, es valorable como la única repre-

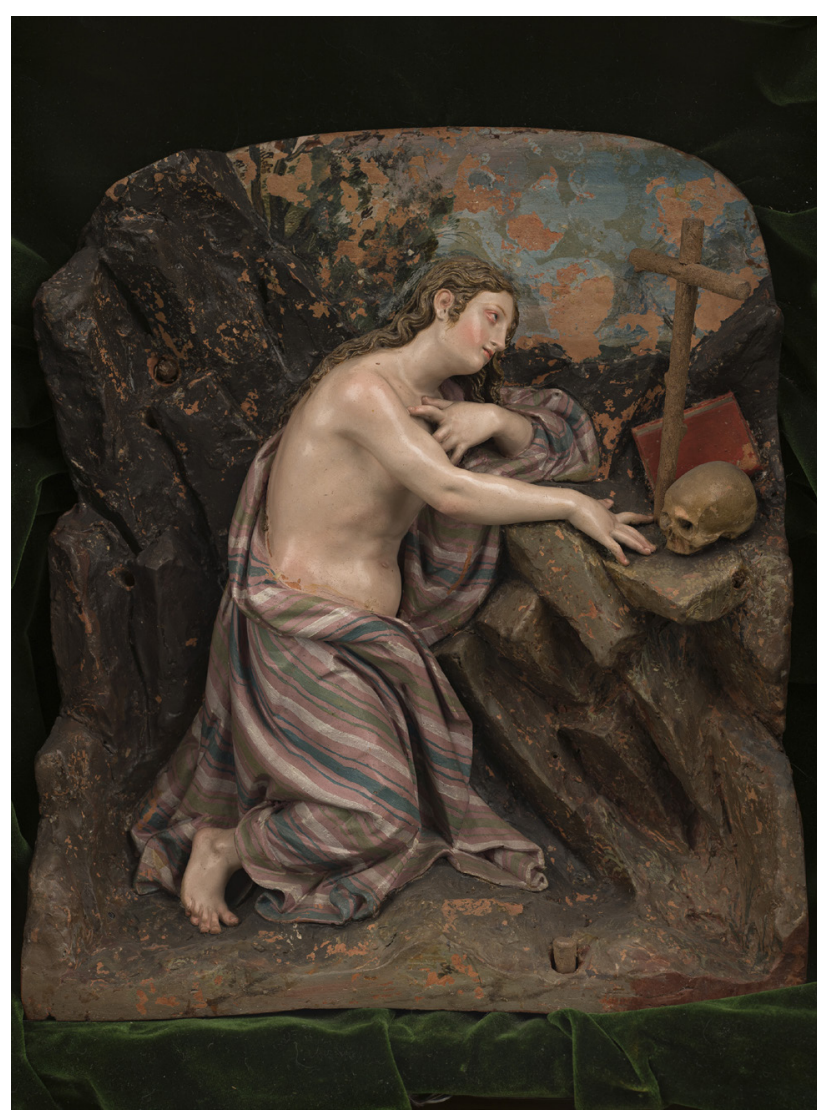

1. Magdalena penitente (general). Miguel Jerónimo García y Jerónimo Francisco García, llamados «hermanos García». Escultura en relieve. Barro modelado, cocido y policromado al seco. Hacia 1620-1630. Colección particular

sentación anatómica, al menos por ahora, que acerca a los autores a un arte de tono profano aun siendo de planteamiento y provecho moralizante.

En primer plano, la figura de la Magdalena aparece en una postura medio erguida medio arrodillada de difícil equilibrio, pero que subraya su intensa actitud de adoración y 


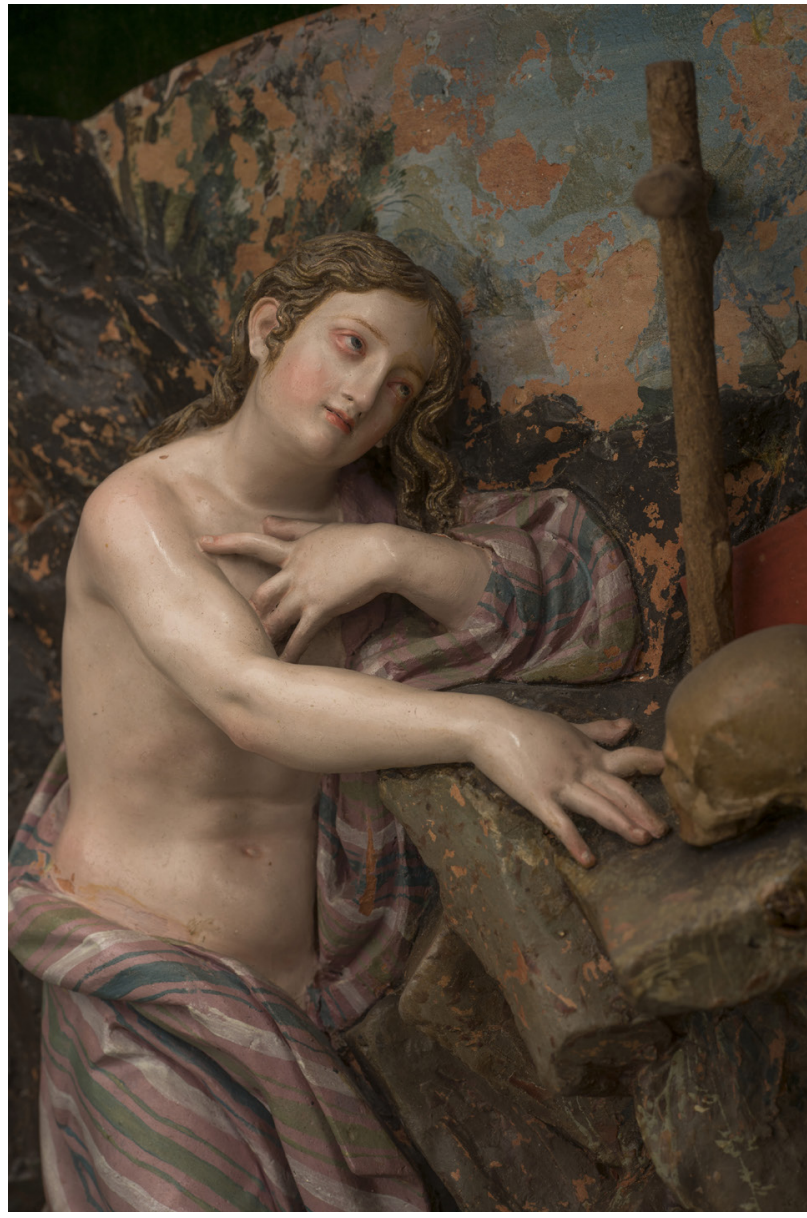

2. Magdalena penitente (detalle). Miguel Jerónimo García y Jerónimo Francisco García, Ilamados «hermanos García». Escultura en relieve. Barro modelado, cocido y policromado al seco. Hacia 1620-1630. Colección particular

postración. La imagen queda emplazada en una vasta y compacta masa de rocas que trazan, en conjunto, una rotunda diagonal en base a la linealidad en la que quedan dispuestos los cantos donde, a su vez, quedan practicados tres orificios que sirven para anclar con pernos la escultura a una más que segura primitiva urna o a un retablo.

Dentro de este fondo que actúa de segundo plano y formando un altar de vanitas, la representada se acompaña de su repertorio alegórico más tradicional: un libro -representando los textos del Evangelio-, una cruz de tipo arbórea y una calavera, que trasladan las privaciones y disciplina, en tanto que únicos bienes materiales, de la vida contemplativa y penitencial realizada tras la Ascensión de Cristo.
Con un punto de vista alto y como tercer nivel compositivo, se incluye un pequeño horizonte de paisaje pintado que completa y enriquece en sensación de profundidad la escena. A pesar de la poca definición en que se halla respecto al estado de conservación, la parte central queda dominada por un cielo y los extremos por masas de vegetación.

La Magdalena se muestra con un juvenil rostro de proporciones cuadradas y facciones angulosas, por el cual recorren cuatro lágrimas. Los ojos con el iris azulino, que contrasta con el subido color rosado de los parpados donde se dibujan las pestañas, adoptan una mirada cenital y abstraída -casi en trance- que parecen buscar el significado de su propia mortalidad, enfatizado, además, por el ligero ladeamiento de la cabeza que la dota de una animación vital de gran arrobo espiritual que concentra toda la carga emocional [2]. La cabeza que se proyecta adelantada hacia la cruz contribuye, de manera potente, a focalizar la atención visual del devoto fiel en este elemento e invita a su veneración y rezo.

El cabello suelto y partido en gruesas crenchas de suaves ondas rizadas se extiende largo y espeso por la espalda [3], tratándose igualmente del atributo por antonomasia de la imagen literaria y artística de la Magdalena -que para la época simbolizaba también desnudez-, quien se pensaba secó los pies de Jesús con sus cabellos confundiéndola con la prostituta del Evangelio de san Lucas y con la hermana de Marta y Lázaro del Evangelio de san Juan. Con la intencionalidad de procurar un mayor verismo en el acabado, las puntas finales de los mechones se concluyen con el dibujo de distintos pelambres a punta de pincel.

Típico de los García es la longitud procurada al cuello, piernas y brazos -donde se advierte una suave tensión de los músculos-, mientras que el torso se ejecuta robusto con abdominales marcados y el bajo vientre algo blando. Cabe destacar la manera un tanto dislocada de colocar los dedos de las manos en el pecho y la peña aportando una gestualidad que transmite fortaleza y pasión.

Finalmente, una ampulosa y envolvente tela se dobla a capricho desde los hombros hasta el suelo -dejando el tronco y un pie visto- que se presenta combinando grandes pliegues abiertos y profundos -generando planos muy sombreados- que dibujan vibrantes contornos que agracian a la imagen en aplomo y movimiento. El dibujo del tejido luce el típico rayado hebreo. Esta es otra novedad para los García 
al variar la habitual monocromía empleada en la caracterización de los ropajes de sus esculturas².

En conjunto, la pieza posee un gran virtuosismo determinado por su vigoroso modelado y la minuciosidad descriptiva en la exposición de detalles -la oreja es ejemplo de extraordinaria labor de miniatura al recrear la fisionomía de las fosas y el orificio auditivo-. La policromía realizada con finas veladuras a pulimento, sin ser excesivo, es contrastada sin apenas matices y pródiga igualmente, en la inclusión de detalles caso de las pequeñas hojas pintadas que se reparten por la base de los riscos.

Sobre influjos artísticos directos, distintos estudios han puesto de manifiesto que estampas alemanas, italianas y holandesas de los siglos XVI y primer tercio del XVII fueron el medio para arbitrar sus ideas los García ${ }^{3}$. Su método material e intelectual se basaba en la selección de un modelo visual, actuando de primeras imágenes preparatorias, que interpretaban y modificaban para crear una obra nueva ofreciendo el auténtico yo creativo de los artistas. Trabajos que eran afrontados mediante la división de responsabilidades donde Jerónimo Francisco ejercía de escultor y Miguel Jerónimo de pintor.

En este caso, la estampa la Magdalena (1609) de Willem van Swanenburgh (1580-1612), abierto a partir de un dibujo de Abraham Bloemaert (1566-1651), permite situar el préstamo temático y formal en la concepción de la escultura, denotando aproximaciones en algunos aspectos de la composición: el encorvamiento del cuerpo, la posición del brazo sobre el pecho y la grafía del pelo y la calavera.

Sin embargo, la hechura refinada y atractiva del rostro y del cuerpo se alejan de la citada fuente -que acusa una pose más estatuaria- y nos plantea una conexión clara con el arte italiano clásico. Siguiendo a García Luque (2008: 179-256), es de sugerir que otra referencia artística conocida y empleada por los García sean los tipos femeninos creados por Tintoretto (1560-1635) y que fueron ampliamente difundidos mediante grabados de reproducción debidos a la mano de Agostino Carracci (1557-1602). A partir de dichos modelos, los hermanos artistas procederían a espiritualizar las representaciones de las iconografías.

Quedaría sin una contestación precisa las condiciones que motivaron la obra, su procedencia ${ }^{4}$ y cronología 5 .

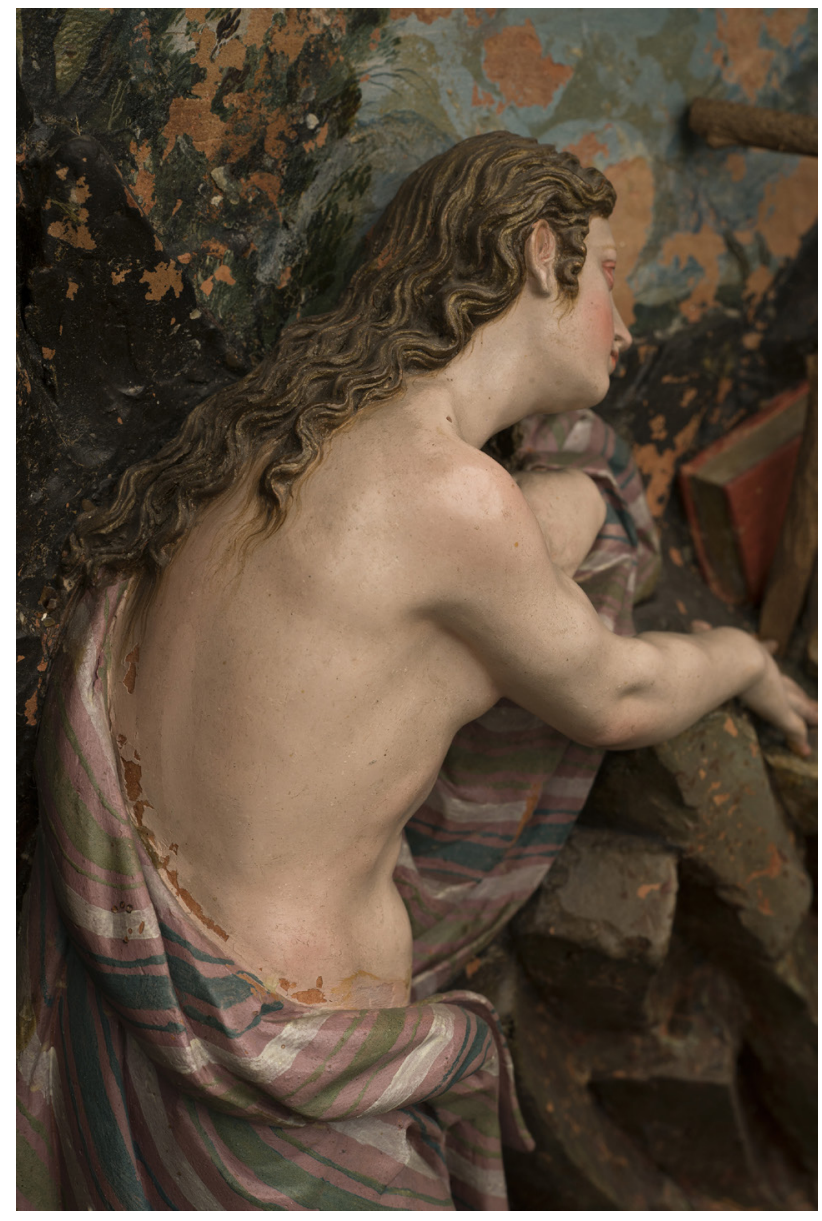

3. Magdalena penitente (detalle). Miguel Jerónimo García y Jerónimo Francisco García, Ilamados «hermanos García». Escultura en relieve. Barro modelado, cocido y policromado al seco. Hacia 1620-1630. Colección particular

Lo probable es que perteneció a una iglesia o, cuanto más, a un convento donde la figura de la Magdalena encarnaba principios y valores de la vida monástica relacionados con la meditación y la expiación de pecados. En cualquiera de los supuestos, su destino de uso sería la devoción y oración íntima y cercana en una capilla que coadyuva a su vez, a la visualización detenida y profunda de la escultura. Sobre su ejecución, es de apuntar a las décadas de 1620 o 1630 por la plena madurez de estilo que presenta basándonos en comparativas a otros relieves fechados. 


\section{Notas}

1 En un reciente artículo anotaba Manuel García Luque, sin aportar una imagen, la existencia al menos de una Magdalena inédita de los García en una colección de Granada, donde: «la santa, de perfil y semiarrodillada, se encuentra exenta por haber perdido el fondo» (2017: 381). Aunque la posición descrita es semejante a la pieza aquí atribuida, la misma presenta un fondo lo que hace pensar que sea otra obra la referida; hecho razonable considerando la repetición escultórica que sobre un mismo tema acostumbraban hacer los artistas introduciendo ciertas variaciones y novedades. También en colección particular granadina, conocemos otra Magdalena penitente calificable de copia coetánea a la escultura que presentamos. La figura, aun con igual composición de postura oblicua y en escorzo, difiere por el tono azulado empleado en la vestimenta, el mayor tamaño concedido al paisaje y en la menor perfección de su modelado.

2 Un parecido dibujo, aunque menos resaltado, se aprecia también en el velo de la Dolorosa de los García del convento de Nuestra Señora de los Ángeles de Granada.

3 García, 2008: 179-256; Romero, 2009: 53-83

4 Según testimonio de la propiedad, la escultura se integró en la colección familiar al menos a finales del siglo XIX desconociendo su ubicación de origen. Hasta la actualidad, se ha trasmitido por herencia aunque no hay registro en las testamentarias realizadas.

5 Sin haber podido verificarse, el reverso pudiera tener inscrita la fecha de realización.

\section{Bibliografía}

GARCÍA LUQUE, Manuel (2017), «Un retrato biográfico de dos escultores en la sombra: los hermanos Miguel Jerónimo y Francisco Jerónimo García (1576-1639/1644)», Archivo Español de Arte, vol. 90, n. ${ }^{\circ}$ 360, pp. 365-382.

- (2008), «Fuentes grabadas y modelos europeos en la escultura andaluza (1600-1650)», en GILA MEDINA, Lázaro (coord.), La consolidación del Barroco en la escultura andaluza e hispanoamericana, Universidad de Granada, Granada, pp. 179-256.

ROMERO TORRES, José Luis (2009), «Los Hermanos García. Sculptors, Painters and Brothers in Sixteenth-Century Granada. An Examination of their Work and Shift towards Naturalism in Andalusian Baroque Sculpture», en The Mystery of Faith. An Eye on Spanish Sculpture 1550-1750, Matthiesen y Coll\&Cortés, Turín, pp. 53-83. 